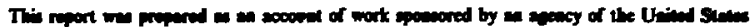

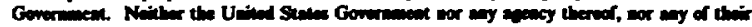

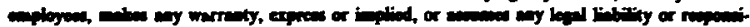

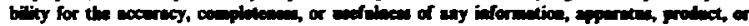

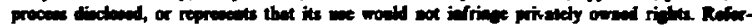

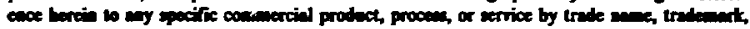

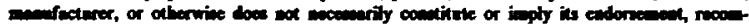

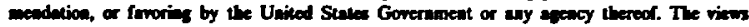
and opicions of anthore expresed herein do not ecesurily state or reflect those of the Unilad States Governmeat or any epeacy theroof.

\title{
SHIELDING CONSIDERATIONS FOR NEUTRAL-BEAM INJECTION SYSTEMS
}

\author{
LEL--15857
}

DE83 013294

\author{
Xavier de Seynes
}

\author{
Nuclear Engineering \\ Lawrence Berkeley Laboratory \\ University of California \\ Berkeley, California 94720
}

This work was supported by the Director, Office of Energy Research, Office of Fusion Energy, Development and Technology Division of the

U.S. Department of Energy under Contract No. DE-AC03-76SF00098. 
ii 


\section{CONTENTS}

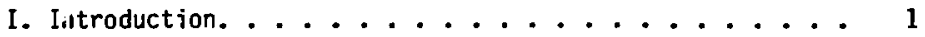

IA. Design of the NBIS Beamline for FED. ....... 3

II. Calculational Method. ............. 5

IIA. Characteristics of MCNP .......... 5

IIB. Establishing the $3-0$ Geometry in MCNP ...... 6

IIC. The Model for the Incident Current Density. . . . 9

III. Variation of Reentry Duct Depth . . . . . . . . . 12

IV. Variation of Thickness of Duct Shield . . . . . 15

V. Variation of Shielding Material ......... 18

VI. Source Type Comparison. . . . . . . . . . 20

VII. Activation of the Neutral Beam Injector ....... 22

VIII. Conclusion. . . . . . . . . . . . . 25

Acknowledgements. ................ 26

References................... 27

Figure Captions ................... 29

Appendix A : Elemental Composition of Concrete. . . . . . 31

Appendix B : Neutron Point Source Spectrum. . . . . . . . 32

Appendix C : Specification of Sources in MCNP ....... 33

Appendix D: Mass Contributions in NBI. ........ 36

Appendix E : Cell-Surface and Surface Cards for Duct

Shield Without Liner and Reentry ....... 38

Appendix $F$ : Cell-Surface and Surface Cards for Duct

Shield With Liner and Reentry. ........ 40 


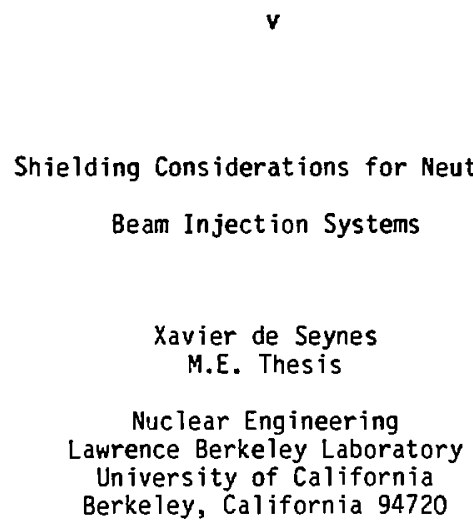

Abstract

Results of a study on the geometry of an FED-A Neutral Beam Injector beamline duct shield are presented. Also included is a calculation of dose rates, as a function of time, from an activated MBI.

The shielding investigations consisted fo varying the parameters of the geometry and transporting particles through it using the MCNP Monte-Carlo code. The dose rates were calculated by the ACDOS3 code using realistic MCNP results.

A final-to-incident flux ratio of $6.5 \times 10^{-7}$ can be achieved through the use of a $65.5 \mathrm{~cm}$ reentry duct. This is for a realistic source and pure water shielding material. The activated NBI produced a dose rate of $15.9 \mathrm{mrem} / \mathrm{hr}$ two and a half days after shutdown of the reactor. 


\section{Introduction}

The most successful and hence the most popular technique for heating magnetically confined plasma to thermonuclear temperatures today consists of the injection and capture of energetic neutral hydrogen atoms. The injected fuel particles traverse the vacuum and external magnetic field unhindered and become trapped in the confinement region by charge exchange and ionizing collisions, subsequently their energy is shared with the target plasma by Coulomb collisions.

There are several requirements for the parameters of a neutral beam injection system (NBIS):

1) The neutral particle energy must be high enough to assume adequate penetration into the plasma before ionization and trapping occurs.

2) The beam power deposited in the target must be $h$ igh enough to provide the desired heating of the plasma.

3) The beam composition and energy spread must be compatible with 1) and 2).

4) The pulse length and repetition rate must be consistent with the goals of the application.

It is witri respect to points 1) and 2) and in the following context that an NBIS based on negative-ions should be selected for a backup heating system for the Fusion Engineering Device (FED).

The system operation, for positive ion beams, is briefly as follows: A deuterium plasma is created in the plasma generator by 
means of a high-current discharge. Ions from this plasma are accelerated in a carefully designed multi-electrode structure. The ions then pass through a neutralizer containing deuterium gas and a fraction becomes neutralized by charne exchange collisions. Remaining ions are removed from the beam by the sweep magnet and collected by the ion beam dump. The vacuum pumps distributed along the beam line remove most of the gas emerging from the neutralizer and the ion beam dump, and must maintain the pressure between the sweep magnet and the entrance port at a sufficiently low value so that very little of the neutral beam is reionized (Figure 1 ).

How, in Figure 2, it is seen that the efficiency with which neutral bøams are formed from positive ions decreases rapidly with increasing particie energy and at proton energies above $75 \mathrm{keV}$ (or deuteron energies above $150 \mathrm{keV}$ ) drops to below 30 percent. Since future beamdriven systems are likely to require energies well above $150 \mathrm{keV}$, it is essential that means be developed for the improvement of neutralbeam production efficiency. One of the possibilities is in using negative ions.

Negative ions would be more desirable because the efficiency of conversion of these to neutrals is much higher, as indicated in Figure 2. Hydrogen atoms can attach a second electron filling the is shell to form a stable negative ion with binding energies of $0.75 \mathrm{eV}$. The difference in the efficiencies is not surprising since it is much easier to detach the extra electron from the hydrogen atom than to strip it completely. The efficiency here is given by the ratio of the probabilities for the two processes. ${ }^{a}$ 


\section{IA. Design of the NBIS Beamline for FED}

Figure 1 provides a simplified view of a neutral beam injector system. The geometry here basically consists of a straight NBI transport/shielding duct axis leading directly to the plasma. With the high source strengths in the plasma $\left(2.6 \times 10^{20}\right.$ neutrons per second ${ }^{b}$ in ETF and $6.4 \times 10^{19}$ neutrons per second ${ }^{C}$ in FED), it is obvious that many neutrons would stream directly from the torus through the NBI duct. This radiation increases the heat load an the cryopanels, causes radiation damage to components and also induces radivactivation of the NBI ensemble resulting in a high dose rate inside the unit and, hence, preventing early maintenance after shutdown.

Lillie et al. ${ }^{1}$ have done a study of the protection of neutral beam injectors in ETF and have concluded that a definite problem exists. These authors have made use of the detailed neutronic calculatians performed by Santoro et $a .^{2}$ for the TFTR and have devised corrections for the source strength and geometry to adopt the TFTR results to ETF. Ruby ${ }^{3}$ has applied the same approach to FED and has concluded that streaming is by far the major contributor to the heat load in FED. The present study will, therefore, concern itself exclusively with the propagation of the streaming neutrons in the duct.

\footnotetext{
a Reference 10.

b Based on a plasma power of $740 \mathrm{MH}$ and $17.6 \mathrm{MeV} /$ event

c Baseline design ( $P_{t L}=180 \mathrm{MW}, 38^{\circ}$ average injection angle)
} 
The results obtained by Ruby ${ }^{3}$ indicate that a reduction by a factor of $10^{5}$ in the dose rate calculated to be in the NBI needs to be achieved to meet FEO design objectives. To mitigate problams created by the streaming neutrons in ETF, Lillie et al. ${ }^{1}$ suggested the use of a shield plug which would fali into place to block the beamlines after 6 seconds of operation (ETF was designed to run in the ignited mode after 6 seconds of heating). This solution is not practical in the case of FED since the baseline design requires FED to be run in the driven mode for 106 seconds at a power which is just 40 percent of that in high power operation (with injection). This requires that an alternative solution be found for the baseline case which would presumably suffice also for the high power mode.

Ruby has studied a proposal to solve the problem in a different manner, namely by deflecting the accelerated heams before they are neutralized, so that the ion source and the accelerator structure can be out of the line of sight of the streaming neutrons and gamma rays. At approximately the position where these itens were placed on the original FED design, there is placed, instead, a neutron stopper whose design will allow no more than $1 \times 10^{-5}$ of the incident neutrons (incident at the plasma end of the duct) to leak out.

It is with the aim of further evaluating the effectiveness of such a proposal that the present study has been undertaken. 
11. Calculational Method

IIA. Characteristics of MCNP

MCNP is a general purpose, continuous energy, generalized-geometry, time-dependent, coupled neutron-photon Monte-Car 10 transport code ${ }^{4}$. It may be used in either of three modes: neutron transport only (this is the mode used in this study), combined neutron-photon transport or photon transport only.

MCNP was originally developed by the Monte Carlo Group (Group X-6) in the Applied Theoretical Physics Division at the Los Alamos National Laboratory.

The code compiles under the FTN-4 compiler with the Livermore Time Sharing System (LTSS) operating system on the LoS Alamos CDC 7600's and under the CFT complier with the CRAY Time Sharing System (CTSS) operating sysem on the Los Alamos CRAY-1's.

The geometry of MCNP treats an arbitrary three-dimensional configuration of arbitrarily defined materials (using up to 40 different isotopes chosen from the MCNP cross-section libraries) in geometric cells bounded by first- and second-degree surfaces and some special fourth-degree surfaces (elliptical-tori). The cells are defined by the intersections, unions and complements of regions bounded by the surfaces. The code does extensive internal checking to find input errors and an elaborate geometry plotting capability is available for diagnos is and presentation.

MCNP uses pointwise nuclear cross section data tabulated in libraries on an energy grid that is tailored to each isotope. Crosssections are added at a sufficient number of points to ensure that the 
linear interpolation reproduces the original cross-section tabulation with in the specified tolerance of a few percent (typically about 0.1 to 0.5 percent).

As well as providing five standard sources, MCNP has a provision to allow the specification of a problem-particular source subroutine. Similarly, standard tallies are provided, to be effective at predefined surfaces, points or rings, in the case of detectors. Fluxes, currents, fission numbers and tritium production are examples of standard tallies.

Standard optional variance reduction schemes in MCNP include geometry splitting and Russian roulette, time and energy cutoffs, correlated sampling, analog/implicit capture by weight reduction, forced collisions and source biasing, among others. Finally, MCNP has the capability to calculate eigenvalues for both sub- and supercritical systems.

\section{IIB. Establishing the 3-D Geometry in MCNP ${ }^{a}$}

In the option employed for this problem, MCNP interprets its geonetry in a Cartesian coordinate system. The geometry is described with surfaces that are themselves defined using corresponding cards, and the sense that the cells have with respect to these surfaces.

a Source: Reference 4. 
The sense of a point or cell with respect to a surface can be defired as follows. If $f(x, y, z)=s=0$ is the equation of a surface, then, by definition, all points $(x, y, z)$ for which $s=0$ lie on the surface. But, for those points not on the surface, if $s<0$, they are said to have a negative sense with respect to that surface and those for wich $s>0$ are said to have a positive sense with respect to the surface.

The specification of cells in MCNP is done by listing on a cell card the cell number, material number (this defines the composition, elemental and isotopic, of the medium in the cell) and material density followed by a list of surfaces that bound the cell. After each signed bounding surface (+ or - according to the sense of the cell with respect to the surface) is a list of the cells on the other side of the surface. This description is optional, however. Each surface divides all space into two regions. The code interprets the geometry description as saying that the cell is the intersection, union and/or complement of the listed regions.

The important advantage, as far as computing time is concerned, in specifying otherside cells when defining them, lies in that jefore starting the neutron transport run, MCNF makes ar internal, selfconsistency check on the geometry. The alternative would be finding geometry-specification flaws through aborted runs and lost particles.

The subdivision of the physical space into cells is not necessarily governed only by material differences in various regions but may be 
due to the need to specify unambiguous geonetry or appropriate tallying. It is the surface cards which determine the size and scale of the geametry.

The geometry used here is that of a simplified negative ion beamline module for a 25 MN FED-A. The simplifications include:

1) neglect of curvature at the plasma-end duct entrance.

2) neglect of the first wall shielding thickness.

3) consideration of anly straight duct feature (instead of the curved TFF beam transport structure)

However, these simplifications are, in fact, favorable for a conservative analys is of the effectiveness of the geometry. In order to represent the presence of electrodes in the brar:Lhes, a $5 \mathrm{~cm}$ thick liner composed of aluminum was introduced into the geometry specification. The specification of the geometry does not include the material comprising the walls of the vessel containing the shielding material. The dimensions of the NBIS were obtained from LBL diagram XBL 828-11317 (see Figures 3, 5 and 6).

Figures 5 and 6 are the outputs of the geometry checking facility provided for in MCNP. Working diagrams (Figs. 7 and 8) were deve Toped and cell-surface relationships derived from them. The input data cards corresponding to the geometry of Figures 7 and 8 can be found in Appendix E. Figure 9 shows a modified duct geometry which included liners and a reentry duct. It was on this geometry that most of this study is based. This is justified by the results of Section III. The input data file corresponding to the latter geometry can be found in Appendix F. 
IIC. The Model for the Incident Current Density

The incident current density of neutrons depended on the nature of the investigation of that run.

A plane source parallel to the longitudinal axis of the duct was used to determine the effect of varying the depth of the reentry duct or the material in the duct shield on the neutron current at the NBI end. The justification for this lies in that the angle subtended by the end of the reentry duct as seen from the torus is very small. This means that for non-planar sources, many neutrons would enter the shield and would be useless to the cause of the investigation. It seems therefore, more efficient (for computing time) to assume that those neutrons contributing to the investigation would have followed, through the duct, a planar or near-planar line of trajectory. Nevertheless, this doesn't mean that all neutrons starting at the beginning of the duct get to the end of the straight section; many will enter the shield at the points of constriction, and produce a scattered-neutron component.

This, however, is a reasonable model since using planar sources leads to having a higher fraction of the incident number actually reaching the end of the initial straight section and hence a higher tally (per source particle).

In determining the effect of shield thickness on the neutron current out of various side surfaces, a cosine source distribution was used. This can be justified by the following considerations.

Lillie et al. ${ }^{5}$ have suggested that the incident neutron current density may be represented using a point source plus a ring source. 
However, not requiring such formal precision and in an attempt to be more time effective, a semi-infinite volume source was assumed at a distance $d$ from the duct entrance (see figure 4).

Now, assuming the volume source emits neutrons isotropically, then the:

number of neutrons emitted in volume $d A d x=Q d A d x$

number of neutrons reaching a from $d A d x=\left(Q / 4 \pi L^{2}\right) d A d x(a \cos \theta)$ $d I=$ number of neutrons reaching a from column $d A$

$$
\begin{aligned}
& =\frac{a Q d A}{4 \pi} \int_{d}^{\infty} d x \frac{\cos \theta}{L^{2}} \\
d I & =\frac{a Q d A}{4 \pi} \int_{d}^{\infty} \frac{d+x}{\left((d+x)^{2}+r^{2}\right)^{3 / 2}} d x \\
& =\frac{a Q d A}{4 \pi} \frac{1}{\ell} \\
& =\frac{a Q d A}{4 \pi} \frac{\cos \theta^{\prime}}{d} .
\end{aligned}
$$

ie $\quad, \pi \cos \theta^{\prime}$.

This use of this model is conservative in that the real source is finite in extent in any dimension: when collapsing one of the dimensions of this volume source to produce a sheet source perpendicular to the duct axis but still at a distance $d$ from the duct entrance, it can be shown that $\mathrm{J} \alpha \cos ^{3} \theta^{\prime}$. 
The real source description probably lies somewhere between the planar and the cosinal, since the orientation of the torus with respect to the duct entrance and axis is such as to generate a relatively stronger near-axial component than that produced by a semi-infinite isotropic source. Details on how the starting point and direction of each cosine-source neutron were specified in the program are to be found in Appendix $C$ to this report. 


\section{Variation of Reentry Duct Depth}

The aim of this investigation was to evaluate the consequences of a reentry duct on the neutron currents from the NBI face of the duct shielding.

A monoenergetic (14.1 MeV) plane parallel source was used. The medium of the shield was taken to be pure water $\left(\mathrm{H}_{2} \mathrm{O}\right)$ at a density of $1.00 \mathrm{~g} / \mathrm{cm}^{3}$. Tallies were defined as follows:

Taily A: Number of particles (neutrons) per soumce particle crossing the end-of-duct surface from one exit port, including the a) uminum liners (area $=4.463 \times 10^{4} \mathrm{~cm}^{2}$ ).

Taliy B: Number of particles (neutrons) per source particle crossing the end-of-duct surface from the region between the inside liners of the two exit ports (see Fig. 6) (area $=2.172 \times$ $\left.10^{5} \mathrm{~cm}^{2}\right)$.

Fluence $A$ and Fluence $B$ were obtained by dividing the corresponding Tallies $A$ and $B$ by the area over which they counted. They are averages. The errors represent a statistical evaluation of the reliability of the taliy figures. However, considering the small magnitudes involved, these errors need not be required to be smal1 in order to make the corresponding statistics of interest. The size of the errors depend on computing time constraints and are a function of the number of source particles started and, to a lesser extent, of the geometry and material composition considered. Even with significant errors, the statistics can give indications as to the expected 
magnitude of a "reliable" result. Also, the geometry used is an approximation to reality wich leads to additional limitations of the results, irrespective of their statistical reliability.

In order to have a reentry duct, it was necessary to add more shielding material than the original design had anticipated. This extra material was introduced between the duct's exit ports in region E of Figure 6 .

In Table 1 it is seen that the flux at the duct's exit port decreases with increasing reentry depth. A reentry duct of $65.5 \mathrm{~cm}$ reduces the exit port flux by a factor of -10 (given the errors). The $65.5 \mathrm{~cm}$ was determined by considering the resultant shielding thickness. At this depth, there is still, with the added material, $164 \mathrm{~cm}$ of shielding directly behind.

Table 1.

\begin{tabular}{ccccc}
\hline $\begin{array}{c}\text { Depth of Reentry } \\
\text { Duct (cm) }\end{array}$ & $\begin{array}{c}\text { Taj1y A } \\
\text { (per s.p.) }\end{array}$ & FLuence A & Error & NPS* \\
\hline 0 & $9.134 \times 10^{-5}$ & $2.046 \times 10^{-9}$ & 13.4 & 480230 \\
32.75 & $3.424 \times 10^{-5}$ & $7.672 \times 10^{-10}$ & 20.7 & 533142 \\
65.5 & $1.143 \times 10^{-5}$ & $2.561 \times 10^{-10}$ & 36.4 & 479475 \\
\hline
\end{tabular}

* NPS - number of particles started at source.

** S.P. - source particle. 
In Table 2, although the errors are high, and in the case of the $32.75 \mathrm{~cm}$ depth, probably overwhelming, it is to be noted that flux B tends to decrease with increasing depth. This might be because, when no reentry duct exists, more neutrons are scattered into and along the duct branches, subsequently scattering through the tallying surface. On the other hand, with a reentry duct and the plane source used, the effect is that of a plane source surrounded by shielding material. The neutrons can, in this case, only diffuse through the medium and are not guided by voids or ducts.

Table 2.

\begin{tabular}{ccccc}
\hline $\begin{array}{c}\text { Depth of Reentry } \\
\text { Duct (cm) }\end{array}$ & $\begin{array}{c}\text { Tally B } \\
\text { (per s.p.) }\left(\mathrm{cm}^{-2} \text { per s.p.) }\right.\end{array}$ & $\begin{array}{l}\text { (\%) } \\
\text { (p) }\end{array}$ & \\
\hline 0 & $1.091 \times 10^{-5}$ & $5.022 \times 10^{-11}$ & 41.00 & 480230 \\
32.75 & $9.622 \times 10^{-7}$ & $4.429 \times 10^{-12}$ & 100.00 & 533142 \\
65.5 & $3.135 \times 10^{-6}$ & $1.443 \times 10^{-11}$ & 70.76 & 479475 \\
\hline
\end{tabular}

More reliable results are needed to establish firmer hypotheses. Eventualiy, optimisation of reentry duct depth might be achieved with more data. 


\section{Variation of Thickness of Duct Shield}

The a im here was to evaluate the flux of leaking neutrons through the sides of the duct shield. Two tallying surfaces were considered and dose rates were calculated.

A monoenergetic (14.1 MeV) cosine source was used and the medium was aga in taken to be pure water at $1 \mathrm{~g} / \mathrm{cm}^{3}$. The tallies were defined as follows:

Tally C: Number of particles (neutrons) per source particle crossing the vertical side surface between the first duct constriction and the branching shield (Area $=2.385 \times 10^{5} \mathrm{~cm}^{2}$ for mdst $=77.5 \mathrm{~cm}$ ).

Tally D: Number of particles (neutrons) per source particle crossing the vertical side surface of the last duct section (see Figure 6) (Area $=1.036 \times 10^{5} \mathrm{~cm}^{2}$ for Lsst $=62 \mathrm{~cm}$ ).

The tallying surface $C$ was defined assuming that the first wall shielding (which reaches up to a little beyorid the level of the first duct constriction) would suffice in blocking those neutrons crossing the side surface before that level in this geometry.

It was also assumed that the number of neutrons contributing to Tally $D$ was independent of the mid-duct shield thickness in the range under investigation. This assumption was shown to be valid (in the geometry-specific neutron population distribution included in the computer outputs).

Fluences $C$ and $D$ are defined as in Section IIl. The mid-duct shield thickness, MDST, is the thickness of the vertical side shield between the first and the second duct constrictions. It will be from 
this region that most of the leaking neutrons will exit, this being mostly due to the cosine nature of the source. The last section shield thickness, LSST, is the thickness of the vertical side shield on the outside of the last duct sections.

Tab1e 3.

\begin{tabular}{|c|c|c|c|c|c|}
\hline $\begin{array}{l}\text { MDST } \\
(\mathrm{cm})\end{array}$ & $\begin{array}{c}\text { Tally C } \\
\text { (per s.p.) }\end{array}$ & $\begin{array}{c}\text { Fluence } C \\
\left(\mathrm{~cm}^{-2} \text { per s.p.) }\right.\end{array}$ & $\begin{array}{l}\text { Error } \\
\qquad(\%)\end{array}$ & NPS & $\begin{array}{l}\text { Dose Rate } \\
\text { (mrem/hr) }\end{array}$ \\
\hline 52.5 & $3.4 .3 \times 10^{-3}$ & $1.476 \times 10^{-8}$ & 2.85 & 302806 & $3.54 \times 10^{3}$ \\
\hline 77.5 & $4.09 \times 10^{-4}$ & $1.715 \times 10^{-9}$ & 6.47 & 462149 & $4.11 \times 10^{2}$ \\
\hline 102.5 & $5.96 \times 10^{-5}$ & $2.436 \times 10^{-10}$ & 21.08 & 272056 & $5.84 \times 10^{1}$ \\
\hline
\end{tabular}

The dose rates were calculated on the bas is that those neutrons which managed to leak out still had the ir initial $14.1 \mathrm{MeV}$ energies. A conversion factor of $2.08 \times 10^{-4}(\mathrm{rem} / \mathrm{hr}) /\left(\mathrm{n} / \mathrm{cm}^{2} \mathrm{~s}\right)^{\mathrm{a}}$ and a duct entrance neutron flux of $5.76 \times 10^{13} \mathrm{n} / \mathrm{cm}^{2} \mathrm{~s}^{\mathrm{b}}$ were used.

Table 4.

\begin{tabular}{lcrrrr}
\hline LSST & Tally C & Fluence D & Error & NPS & Dose Rate \\
$(\mathrm{cm})$ & (per s.p.) & $\left(\mathrm{cm}^{-2}\right.$ per s.p. $)$ & $(\%)$ & & $(\mathrm{mr}$ em/hr $)$ \\
\hline 45.0 & $<3.30 \times 10^{-6}$ & $<3.056 \times 10^{-11}-$ & 302806 & $<7.32 \times 10^{0}$ \\
62.0 & $<3.68 \times 10^{-6}$ & $<3.552 \times 10^{-11}-$ & 272056 & $<8.51 \times 10^{0}$ \\
75.0 & $<2.16 \times 10^{-6}$ & $<2.158 \times 10^{-11}-$ & 462149 & $<5.17 \times 10^{0}$ \\
\hline
\end{tabular}

a Source: Reference 4

b Assuming a neutron wall loading of $1.3 \mathrm{MW} / \mathrm{m}^{2}$ and $14.1 \mathrm{MeV}$ neutrons. 
The results of Table 4 can be interpreted as being due to the relatively small numbers of neutrons that survive until the last duct sections. In the case of the $75 \mathrm{~cm}$ run, the number of neutrons that survived as far as either of the last duct sections, including a!l four liner cells, is 14 (out of the 462149 started). In order to obtain a significant result, the number of neutrons started needs to be much larger: the neutron population is not only affected by the geometrical distance from the source, but aiso by the energy attenuation experienced by surviving neutrons and by the cosine nature of the source itself. 


\section{y. Yariation of Shielding Material}

This investigation is concerned with the material comprising the duct shield. The materials studied were borated water, for its high neutron shielding capacity, lithium carbonate solution, for poss ible tritium breeding, and concrete, for structural implications. The result were also compared to pure water (Section III).

All comparisons here included a $65.5 \mathrm{~cm}$ reentry duct. This remained the same throughout the investigation. A monoenergetic plane source (14.1 MeV) was used.

The tallies and fluences have the same definitions as those in Section III but will be renamed Am and Bm for clarity.

\section{Table 5.}

\begin{tabular}{|c|c|c|c|c|c|}
\hline $\begin{array}{l}\text { Shielding } \\
\text { Material }\end{array}$ & $\begin{array}{l}\text { Density } \\
\mathrm{g} / \mathrm{cm}^{3}\end{array}$ & $\begin{array}{l}\text { Tally Am } \\
\text { (per s.p.) }\end{array}$ & $\begin{array}{c}\text { Fluence Am } \\
\left(\mathrm{cm}^{-2} \text { per s.p.) }\right.\end{array}$ & $\begin{array}{c}\text { Error } \\
(\%)\end{array}$ & NPS \\
\hline Pure water & 1.00 & $1.143 \times 10^{-5}$ & $2.561 \times 10-10$ & 36.4 & 479475 \\
\hline $\begin{array}{l}\text { Borated } \\
\quad \text { watera }\end{array}$ & 1.063 & $3.536 \times 10^{-6}$ & $1.689 \times 10^{-10}$ & 41.0 & 637472 \\
\hline $\begin{array}{l}\text { Lith ium } \\
\text { Carbonate } \\
\text { Solutiona }\end{array}$ & 1.015 & $5.853 \times 10^{-6}$ & $1.311 \times 10^{-10}$ & 71.0 & 279340 \\
\hline Concreteb & 2.4 & $1.008 \times 10^{-3}$ & $2.259 \times 10^{-8}$ & 11.3 & 45584 \\
\hline
\end{tabular}

a Isotopic compositions derived from references 7 and 8 .

b Elemental composition data from reference 9 , see Appendix $A$. 
Table 6 .

\begin{tabular}{llllll}
\hline $\begin{array}{l}\text { Shielding } \\
\text { Material }\end{array}$ & $\begin{array}{c}\text { Density } \\
\text { g/cm }\end{array}$ & $\begin{array}{l}\text { Tally Am } \\
\text { (per s.p.) }\end{array}$ & $\begin{array}{c}\text { Fluence Am } \\
(\mathrm{cm}-2 \text { per s.p.) }\end{array}$ & $\begin{array}{c}\text { Error } \\
(\%)\end{array}$ & APS \\
\hline Pure water & 1.00 & $3.135 \times 10^{-6}$ & $1.443 \times 10^{-11}$ & 70.8 & 479475 \\
$\begin{array}{c}\text { Borated } \\
\text { water }\end{array}$ & 1.063 & $2.358 \times 10^{-6}$ & $1.085 \times 10^{-11}$ & 70.8 & 637472 \\
$\begin{array}{c}\text { Lithium } \\
\text { Carbonate } \\
\text { Solution }\end{array}$ & 1.015 & $2.793 \times 10^{-6}$ & $1.286 \times 10^{-11}$ & 100.0 & 279340 \\
$\begin{array}{c}\text { Concrete } \\
\text { Concrete }\end{array}$ & 2.4 & $1.041 \times 10^{-3}$ & $4.792 \times 10^{-9}$ & 9.8 & 45584 \\
\hline
\end{tabular}




\section{Source Type Comparison}

In order to compare the tallies and fluences $A$ and $B$ on the end-ofduct surface due to both a simple plane source and a more realistic cosine source, the following tables are presented. In both cases a monoenergetic source was used (14.1 MeV).

Included in the tables are the results of an en ergy-distributed cosine source. The energy distribution, as tabulated in Appendix B, is that derived by Lillie et a $1 . .^{5}$ In using a cosine source, it was thought appropriate to extract the energy distribution of only the point source used by Lillie et al. 5

A reentry duct $(65.5 \mathrm{~cm})$ gemetry with pure water as shielding material was used.

Table 7.

\begin{tabular}{lllll}
\hline \multicolumn{1}{c}{ Source Type } & $\begin{array}{l}\text { Tally As } \\
\text { (per s.p.) }\end{array}$ & $\begin{array}{l}\text { Fluence As } \\
\left(\mathrm{cm}^{-2} \text { per s.p.) }\right.\end{array}$ & $\begin{array}{c}\text { Error } \\
(\%)\end{array}$ & NPS \\
\hline Plane $(14.1 \mathrm{MeV})$ & $1.143 \times 10^{-5}$ & $2.561 \times 10-10$ & 36.4 & 479475 \\
Cosine $(14.1 \mathrm{MeV})$ & $2.718 \times 10^{-6}$ & $6.091 \times 10-11$ & 50.2 & 1272256 \\
$\begin{array}{l}\text { Cos ine and Energy } \\
\text { Distribution }\end{array}$ & $1.428 \times 10^{-6}$ & $3.200 \times 10-11$ & 50.3 & 2547138 \\
\hline
\end{tabular}


Tabie 8.

\begin{tabular}{|c|c|c|c|c|}
\hline Source Type & $\begin{array}{l}\text { Tally Bs } \\
\text { (per s.p.) }\end{array}$ & $\begin{array}{l}\text { Fluence Bs } \\
\left(\mathrm{cm}^{2} \text { per s.p.) }\right.\end{array}$ & $\begin{array}{l}\text { Error } \\
(q)\end{array}$ & NPS \\
\hline Plane (14.I MeV) & $3.135 \times 10^{-6}$ & $1.443 \times 10^{-11}$ & 70.76 & 479475 \\
\hline Cosine $(14.1 \mathrm{MeV})$ & $<7.86 \times 10^{-1}$ & $<3.618 \times 10^{-12}$ & -- & 1272256 \\
\hline $\begin{array}{l}\text { Cosine and Energy } \\
\text { Distribution }\end{array}$ & $<3.93 \times 10^{-7}$ & $<1.809 \times 10^{-12}$ & -- & 257138 \\
\hline
\end{tabular}

It can be seen from Table 7 that there is a factor of 4 or 5 difference in the results depending on the source type. The reasonably small difference between a plane and a cosine source might be due to the neutrons of both sources entering the duct shield at the constrictions and producing a scattered neitron component. This component is probably greater in the cosine source result.

As for the energy-distributed cosine source, the small difference in the results might be due to the large majority of fast neutrons generated. Eighty percent of the source neutrons were assumed to have energies above $10.0 \mathrm{MeV}$.

These difference factors may be applied to all preceding results (dealing with plane sources) in an attempt to make them more realistic. The advantage of having used a plane source, however, can be judged by comparing the relationship between the percentage error and the number of particles started at the source, NPS, or, its proportional variant, computation time. 


\section{Activation of the Meutral Beam Injector}

The activation of the neutral beam injector by the neutrons exiting the duct and the resulting dose rate can be calculated, ${ }^{11}$ as a function of time with the program "ACDOS3". Activation of the KBI, exclusive of the vacuum system and the other components to which it is attached, is important. This is because, for maintenance, the MBI is detached from the system remotely and is moved to an adjacent ma intenance area. Dose rates from an activated NBI would determine maintenance time.

The input data file for ACDOS3 inciuded the MCNP results of the cosine--source and source-neutron energy-distribution mentioned in Section VI. Ths run required 127.8 minutes of CRAY-1 time and used $2,547,138$ source particles. The geometry included a $65.5-\mathrm{cm}$ reentry duct. The emergent neutrons, at the NBI end, were tallied in 3 energy groups, whose boundaries were; $1.0 \times 10^{-11} \mathrm{MeV}, 0.4 \times 10^{-6} \mathrm{MeV}$, $10 \mathrm{MeV}$ and $15 \mathrm{MeV}$. Pure water was the shielding material.

To obtain the source flux, it was assumed, as in Section IV, that the neutron wall loading was $1.3 \mathrm{MW} / \mathrm{m}^{2}$ due to $14.1 \mathrm{MeV}$ neutrons, with a duty factor of $0.5,8$ hours on and 16 hours off, for 5 days.

The energy tally of existing neutrons was as follows:

Energy Group (MeV)

$1.0 \times 10^{-11}--4.0 \times 10^{-7}$

$4.0 \times 10^{-7} \quad--10.0$

10.0
Fluence (cm-2 per s.p.)

$<8.797 \times 10^{-12}$

$3.200 \times 10^{-11}$

$<8.797 \times 10^{-12}$ 
Contributions toward the NBI mass were considered from 30 isotopes as listed in Appendix D. The NBI itself was approximated by a solid self-absorbing sphere, $60 \mathrm{~cm}$ in diameter. Tiwelve times were chosen at 5 hour intervals for the evaluation of the dose rate received ty an observer $10 \mathrm{~cm}$ away from the side of the sphere.

Table 9 presents the dose rates calculated by ACDOS2 using the above data.

Table 9

Time (hrs)

Dose Rate (mrem/hr)

5
10
15
20
25
30
35
40
45
50
55
60

$2.01 \times 10^{2}$

$1.53 \times 10^{2}$

$1.18 \times 10^{2}$

$9.23 \times 10^{1}$

$7.25 \times 10^{1}$

$5.71 \times 10^{1}$

$4.53 \times 10^{1}$

$3.62 \times 10^{1}$

$2.91 \times 10^{1}$

$2.37 \times 101$

$1.94 \times 10^{1}$

$1.61 \times 10^{1}$

Of $a \vdots 1$ the isotopes included in the specification of the NBI mass, Copper-63, Copper-65, Titanium-48 and Aluminum-27 were found to be largely responsible for the magnitude of the dose rates. Table 10 compares the dose rate due to these and the rest of the isotopes after 5 hours. 
Table 10

Isotope

Copper-63

Copper-65

Titan i um-48

Aluminum-27

Mo lybdenum-98

Magnes ium-55

All remaining isotopes
Dose Rate (mrem/hr)

$1.66 \times 10^{2}$

$6.73 \times 10^{0}$

$8.05 \times 10^{0}$

$9.91 \times 10^{0}$

$3.41 \times 10^{0}$

$5.06 \times 10^{0}$

$1.84 \times 10^{0}$ 


\section{COMCLUSION}

The MCNP code was used to study the geometry of an FED-A Neutral Beam Injector beamline. Variation of beamline parameters was undertaken to the extent of the available computer time. Significant conclusions are:

1. The introduction of a reentry duct of $65.5 \mathrm{~cm}$ depth and of shielding material between the exit ports in the duct geometry was found to additionally reduce the neutron flux at the NBI by a factor of about 10 .

2. The thickness of the duct shield was crucial to the dose rate outside of it during reactor operation. A reduction by a factor of 7 could be reached by increasing the mid-duct shield thickness from $77.5 \mathrm{~cm}$ to $102.5 \mathrm{~cm}$.

3. Lithium carbonate solution and borated water were shown to be effective shielding materials providing a final-to-incident flux ratio of $2.6 \times 10^{-6}$ and $4.3 \times 10^{-6}$, respectively (with $65.5 \mathrm{~cm}$ reentry duct). In comparison, pure water provided a flux ratio of $5.7 \times$ $10^{-6}$. Concrete gave less acceptable results.

4. The type of source used had a relatively smalt effect on the results. However, using a cosine-biased, energy-distributed source did reduce the neutron flux at the exit ports by a factor of about 10 compared to a monoenergetic plane source.

5. The dose rate from a realistically activated neutral beam injector was found to be $2.00 \times 10^{+2} \mathrm{mrem} / \mathrm{hr}$ five hours after shutdown and $1.59 \times 10^{1} \mathrm{mrem} / \mathrm{hr}$ after 2.5 days. 


\section{ACKNOWLEDEMENTS}

I am indebted to Professor Lawrence Ruby who offered untiring assistance throughout the study, to Ludmilla Soroka for helping me to understand the MFE computer and to Catherine S. Martin who is an author of the ACDOS3 code. 


\section{REFERENCES}

1. R. A. Lillie, R. T. Santoro, and R. G. Alsmiller, Jr., "Estimated Nuclear Effects in the Neutral Beam Injectors of a Large Fusion Reactor," Oak Ridge National Laboratory Report ORNL/TM-7526, December 1980.

2. R. T. Santoro, R. A. Lillie, R. G. Alsmiller, Jr., and J. M. Barnes, Nucl. Sci. Eng. 70, 225 (1979).

3. L. Ruby, "The Shielding of Neutral Beam Injectors in FED," unpublished memoranduni, Lawrence Berkeley Laboratory, August 1982.

4. "MCNP-A General Purpose Monte-Carlo Code for Neutron and Photon Transport," LA-7396-M (Rev) Version 2B, Los Alamos Monte-Carlo Group, Los Alamos National Laboratory (1981).

5. R. A. Lillie, R. T. Santoro, R. A. Alsmiller, Jr., J. M. Barnes, "Neutron and Gamma ray Streaming Calculations for the ETF Neutral Beam Injectors," Oak Ridge National Laboratory Report ORNL/TM-7705, February 1981.

6. U.S. Department of Energy, "The Fusion Engineering Device," U.S. Department of Energy Report DOE/TIC-11600, Volume 2, October 1981.

7. C. M. Lederer, J. M. Hollander, I. Periman, "Tabie of I sotopes," Wiley, 6th Edition, 1967.

8. C. 0. Hodgman, R. C. 'east, S. M. Selby, Handbook of Chemistry and Physics, Chemical Rubber Publishing Company, 40th Edition, 1958.

9. Blizzard, Reactor Handbook, 2nd Edition, Volume III, part B., Interscience, 1962. 
10. W. B. Kunke1, "Neutral Beam Irijection," Lawrence Berkeley Laboratory Report LBL-10447, Accelerator and Fusion Research Division, June 1980.

11. C. S. Martin, "ACDOS3: A Further Improved Neutron Induced Dose Rate Code," Lawrence Berkeley Laboratory Report LBL-14547, Accelerator and Fusion Research Division, July 1982. 


\section{FIGURE CAPTIOHS}

Fig. 1. Neutral beam injection system (schematic).

Fig. 2. Heutralization efficiency as a function of particle energy, where $n=$ power in neutral atoms out/power in ion beam entering neutralizer.

Fig. 3. Negative ion beamline modules with the split-duct feature and without the reentry duct geometry.

Fig. 4. Reference diagram for determining the characteristics of a semi-infinite plane source.

Fig. 5. Profile of NBIS duct. This refers to the geometry defined in the MCNP input data file. The diagram is a cross-sectional view in the vertical plane parallel to the central longitudinal axis of the duct.

Fig. 6. Plan view of NBIS duct geometry in MCNP input file. This is a cross-sectional view in the horizontal plane parallel to the central longitudinal axis of the duct. The surface names refer to results presented in the text.

Fig. 7. Duct geometry: Part 1. Working diagram for the specification of part of the duct geometry. Circled numbers represent cells and non-circled numbers represent the surfaces.

Fig. 8. Duct geometry: Part 2. Working diagram for the specification of the second part of the duct geometry. This geometry does not include liners and reentry duct. Surface 2 is the interface between Figs. 7 and 8 . The cell-surface relation and surface cards describing this geometry (Parts 1 and 2) may be found in Appendix E. 
Fig. 9. Duct geometry: Reentry duct and 1 iners working diagram for specifying the geometry of liners and reentry duct. The cell-surface relation and surface cards of the whole duct with this geometry may be found in Appendix F. 
APPENDIX A

Elemental Composition of a Concrete, ${ }^{a}$ (used in Section $V$ ).

\begin{tabular}{|c|c|}
\hline Element & Gram of Elements per $\mathrm{cm}^{3}$ of Concrete \\
\hline$H$ & 0.02 \\
\hline 0 & 1.116 \\
\hline c & 0.118 \\
\hline Mg & 0.057 \\
\hline Al & 0.085 \\
\hline Si & 0.342 \\
\hline S & 0.007 \\
\hline$k$ & 0.004 \\
\hline $\mathrm{Ca}$ & 0.582 \\
\hline $\mathrm{Fe}$ & 0.026 \\
\hline $\mathrm{Na}$ & 0.011 \\
\hline$P$ & 0.007 \\
\hline Mn & 0.002 \\
\hline
\end{tabular}

a Source: Reference 8 . 


\section{APPENDIX B}

Neutron Point Source Spectrum. ${ }^{a}$

Neutron Lower

Energy $(\mathrm{MeV})^{\mathrm{b}}$
Source
Neutron lower

Energy (MeV) Source

\begin{tabular}{cccc}
\hline 13.5 & $1.21+19$ & $1.50-1$ & $1.21+17$ \\
12.2 & $3.06+16$ & $8.65-2$ & $1.34+17$ \\
10.0 & $3.48+16$ & $3.18-2$ & $1.88+17$ \\
8.16 & $3.18+16$ & $1.50-2$ & $1.19+17$ \\
6.70 & $3.06+16$ & $7.10-3$ & $1.10+17$ \\
5.49 & $3.20+16$ & $3.36-3$ & $1.04+17$ \\
4.49 & $3.12+16$ & $1.58-3$ & $9.92+16$ \\
3.68 & $4.24+16$ & $4.54-4$ & $1.48+17$ \\
3.01 & $5.84+16$ & $1.01-4$ & $1.48+17$ \\
2.47 & $7.94+16$ & $2.26-5$ & $1.05+17$ \\
2.02 & $9.68+16$ & $1.07-5$ & $3.69+16$ \\
1.65 & $1.09+17$ & $5.04-6$ & $2.56+16$ \\
1.35 & $1.20+17$ & $2.38-6$ & $1.61+16$ \\
1.11 & $1.28+17$ & $1.13-6$ & $9.12+15$ \\
$9.07-1$ & $1.16+17$ & $4.14-7$ & $5.51+15$ \\
$7.43-1$ & $1.33+17$ & $1.00-10$ & $2.17+15$ \\
$4.98-1$ & $2.31+17$ & & \\
$3.34-1$ & $1.76+17$ & & \\
$2.24-1$ & $1.50+17$ & & \\
\hline
\end{tabular}

a Saurce: Reference 7.

b Upper Energy Group is $1.49+7$. Read as $1.49 \times 10^{7}$. 


\section{APPENDIX $C$}

When the source desired is not one of the standard sources provided for in MCNP, the user can update the code with a problemspecific source subroutine. The details of this technique may be found in Reference 4, Appendix A.

Presented here is the subroutine used to define a cosine source on a surface. In essence th is subroutine consists of randomly choosing a point on a surface, $(x, y, z)$, and then randomly choosing the az imuthal angle $o$ and the cosine biased polar angle $\theta$ with which a source neutron will leave that point. $\theta$ and $\theta$ are defined using direction cosines, $(u, v, w)$. The geometry developed in this problem was such that the duct axis was parallel to the y-axis. The "IA", "JA", "TME", "WGT", and "ERG" entries refer to the first cell seen by the source neutron, its starting surface, the time after which history scoring is to be started, its initial weight and energy, respectively. For our geometry, the source surface is $100 \times 200 \mathrm{~cm}^{2}$. "RANF(I)" is the random number generator function and "NRN" is the random number counter.

Now, in Section IIC, we have obtained that

$$
\begin{aligned}
& J(\theta)_{\alpha} \cos \theta . \\
& \text { i.e. } J(\theta)=K \cos \theta
\end{aligned}
$$

where $K=$ normalization constant. So, by definition: 


$$
\begin{gathered}
\int_{0}^{\pi / 2}(k \cos \theta) \sin \theta d \theta=1 \quad \text { (see figure 4) } \\
\text { i.e., } k=2
\end{gathered}
$$

and in terms of random numbers; if $V=\cos \theta$,

$$
\begin{aligned}
& \int_{0}^{v} 2 v d v \int_{C}^{R} d r \\
& \text { i.e., } \quad R=v^{2}
\end{aligned}
$$

Independently, can be expressed as

$$
\emptyset=2 \pi R
$$

The subroutine, then, cons is ted of the following FORTRAN 1 ines:

$$
\begin{array}{ll}
\text { NRN } & =1 \\
X & =-50+100 \star \operatorname{RANF}(1) \\
\text { NRN } & =N R N+1 \\
Y & =0 \\
Z & =-100+200 \star \operatorname{RANF}(1) \\
N R N & =N R N+1 \\
\text { PHI } & =6.2832 \star \operatorname{RANF}(1) \\
\text { NRN } & =\text { NRN }+1 \\
V & =S Q R T(\operatorname{RANF}(1)) \\
\text { NRN } & =\text { NRN }+1 \\
U & =S Q R T(1-V \star V) \star \operatorname{COS}(P H I) \\
W & =S Q R T(1-V \star V) \star \operatorname{SIN}(P H I) \\
\text { IA } & =1 \\
\text { JA } & =1 \\
\text { TME } & =0 \\
\text { WGT } & =1 \\
\text { ERG } & =14.1
\end{array}
$$


35

In order to specify a plane source, a new subroutine must be incorporated in the MCNP program. The subroutine employed is identical to that for the cosine source except the $U, V$ and $W$ were set equal to 0,1 and 0 , respectively. In other words, the plane source subroutine was as follows:

$$
\begin{array}{ll}
\text { NAN } & =1 \\
X & =-50+100 * \operatorname{RANF}(1) \\
\text { URN } & =N R N+1 \\
Y & =0 \\
Z & =-100+200 * \operatorname{RANF}(1) \\
\text { RN } & =\text { NRA }+1 \\
V & \geq 1 \\
U & =0 \\
W & =0 \\
\text { IA } & =1 \\
\text { JA } & =1 \\
\text { THE } & =0 \\
\text { HGT } & =1 \\
\text { ERG } & =14.1
\end{array}
$$




\section{APPEWUIX D}

Mass contributions of materials in $\mathrm{MBI}$ (used in Secticn VII) (negligible contributions have been ignored, limits are imposed by ACDOS3)

Isotope

$29 \mathrm{Cu}_{53}$

$29 \cup_{65}$
Abundance

(\%)

69.1

30.9

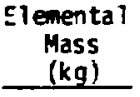

63.56
I sotopic

Mass

(kg)

43.92

19.64

$13 \mathrm{~A}]_{27}$

100.0

9.42

9.42

$22 T i_{46}$

7.98

3.00

$22 \mathrm{~T}_{4} 7$

7.32

2.75

$22 \mathrm{Ti}_{48}$

73.99

37.6

27.82

$22 \mathrm{Ti}_{49}$

5.46

2.05

${ }^{22} \mathrm{~T}_{50}$

5.25

1.97

42Mog2

15.86

2.04

42 Mog 4

9.12

1.17

42M0g5

15.70

2.02

42 Mog6

16.50

12.86

2.12

42 Mog 7

9.45

1.22

42 MOg8

23.75

3.05

42MO100

9.62

1.24

${ }^{80}{ }_{16}$

100.00

8.70

8.70

$25_{55}$

100.00

0.40

0.40 
Isotope

$26 \mathrm{Fe}_{54}$

$26 \mathrm{Fe} 66$

$26 \mathrm{Fe}_{57}$

$145 \mathrm{i}$

$24 \mathrm{Cr}_{50}$

${ }^{24} \mathrm{Cr}_{52}$

${ }^{24} \mathrm{Cr}_{53}$

${ }^{24} \mathrm{Cr}_{54}$

$28_{N i_{58}}$

$28 i_{60}$

$28^{N i_{61}}$

$2 \mathrm{Ni}_{62}$

$2 \mathrm{Ni}_{64}$

${ }^{62} \mathrm{Sm}_{144}$

$62 \mathrm{Sm}_{147}$

$62 \mathrm{Sm}_{148}$

62 sm149 $_{149}$

${ }^{62} \mathrm{Sm}_{150}$

$62 \mathrm{sm}_{152}$

${ }^{62} \mathrm{sm}_{154}$

${ }^{27} \mathrm{CO}_{59}$
Abundance

(E)

5.94

91.78

2.28

ignored

4.31

83.76

9.55

2.38

67.76

26.16

1.25

3.66

1.16

3.15

15.02

11.28

13.85

7.43

26.70

22.60

100.00

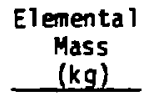

Isotopic

Mass

(kg)

0.37

6.25

5.74

0.14

ignored

1.21

1.45

0.14

ignored

0.62

0.24

0.91

ignored

ignored

ignored

ignored

0.20

0.11

1.34

0.19

ignored

0.37

0.31 


\author{
APPERDIX E
}

Data input cards for the specification of geometry in Figs. 7 and 8.

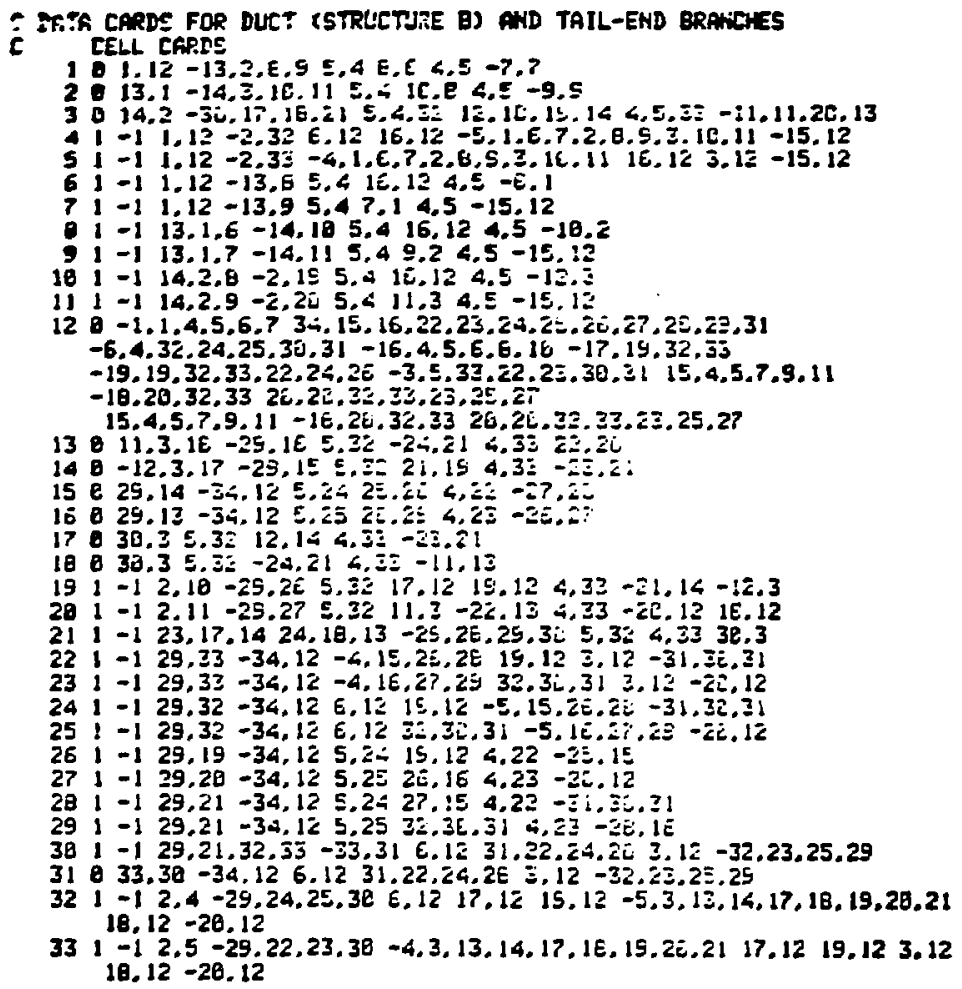


APPENDIX E (Cont'd)

c surface cards

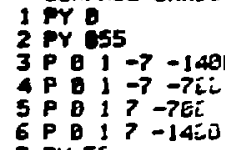

6 P D 1
7 PX $5 E$

8) PX -50

9 PX 22.5

10 PX -22.5

11 PX 17.5

12 PX -17.5

13 PY 146

14 PY 400

15 PX 125

16 PX -125

17 P 35.40 Q242

$10 P-33.404242$

19 PX -342

28 PX 342

21 P $35.40454=$

22 P -35.4 Q $4 E 42$

$23 \times 35.485051$

$24 P-35.4$ E 5051

25 PX -285

$26 \mathrm{PX} 285$

27 PX -282

28 PX 282

29 PY 1055

30 pr 942.777777770

31 PX -155

32 PX 155

33 PY $110 ?$

34 Pr 1182 


\section{APPENDIX $F$}

Data input ca-ds for the specification of the geometry in Fig. 9 completed by that in Figs. 7 and 8 .

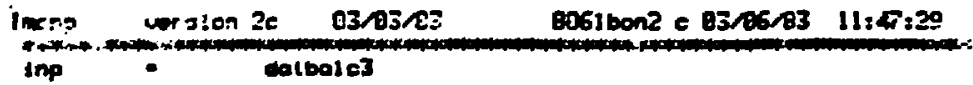

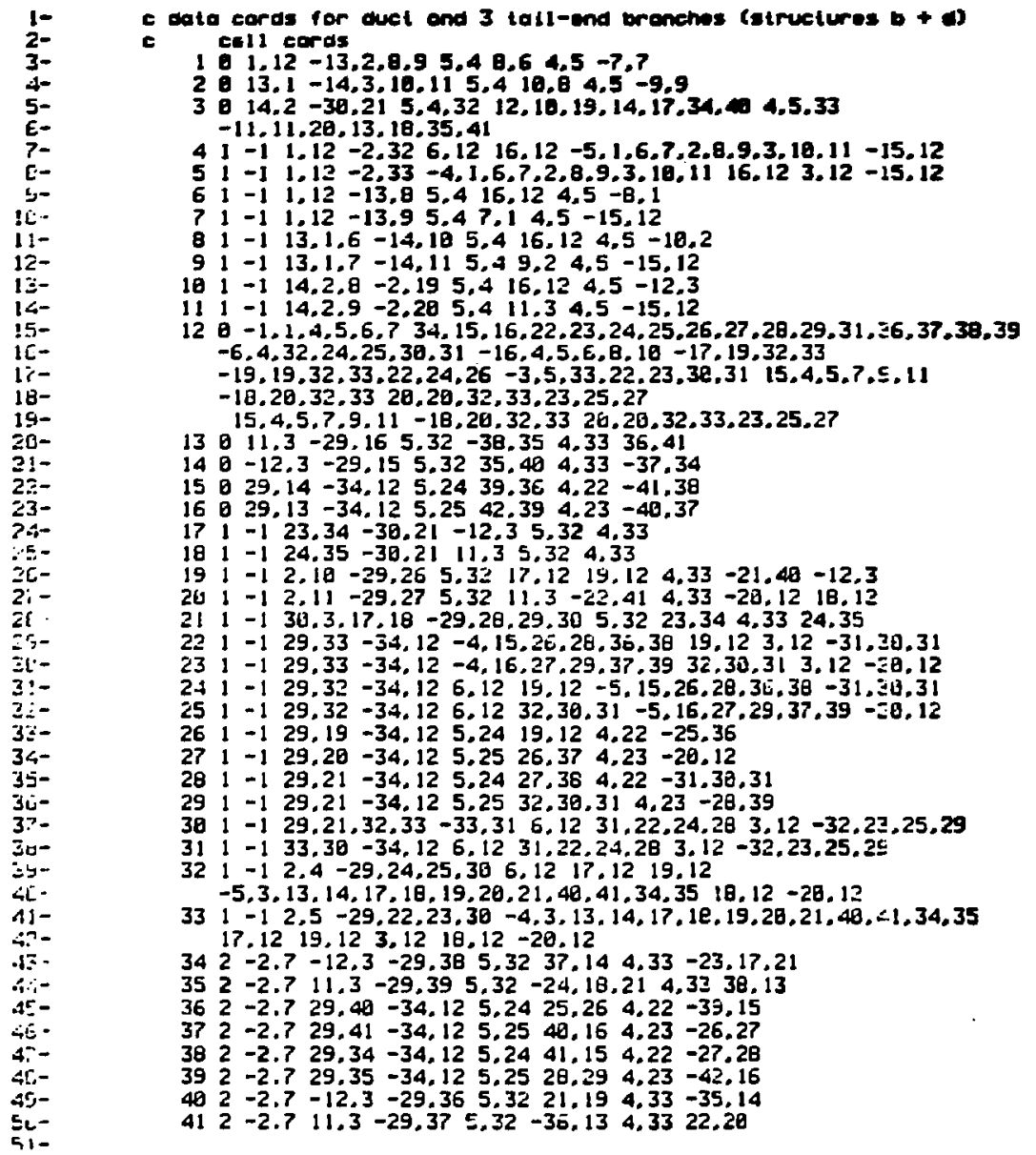




\section{APPEKDIX $F$ (Cont'd)}

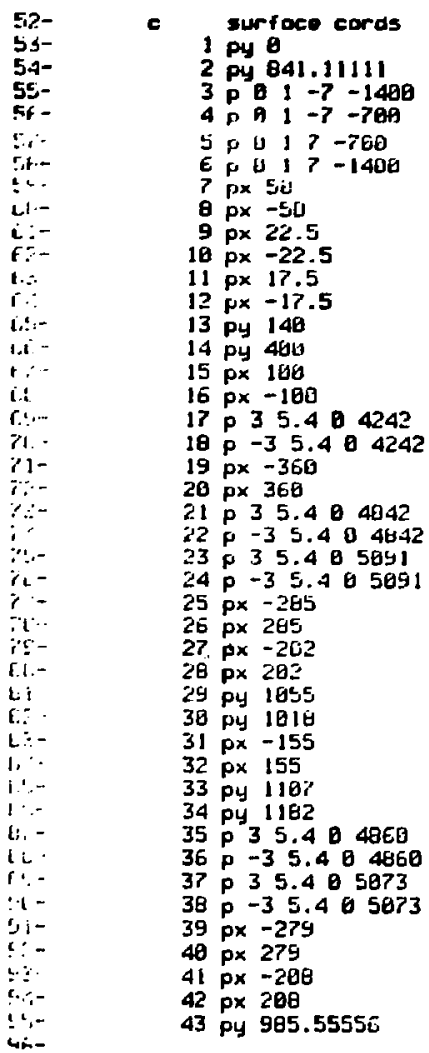




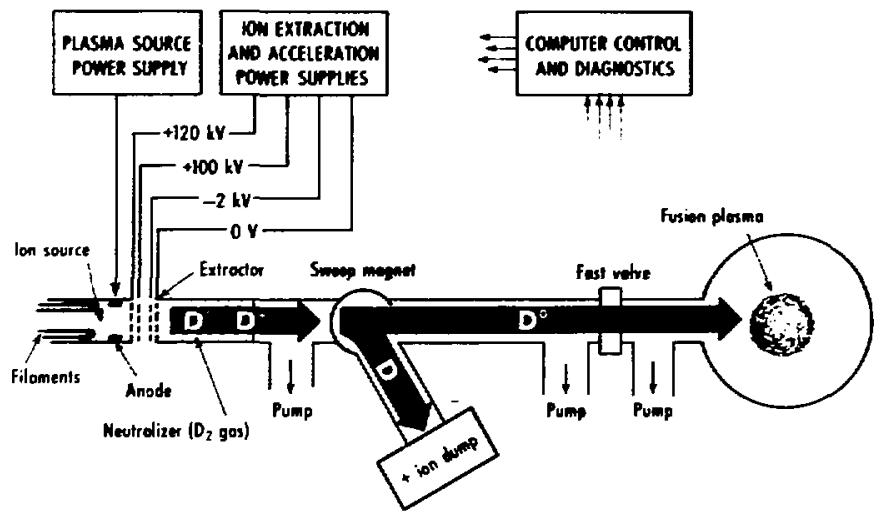

CBB 751-8186

Figure 1 . 


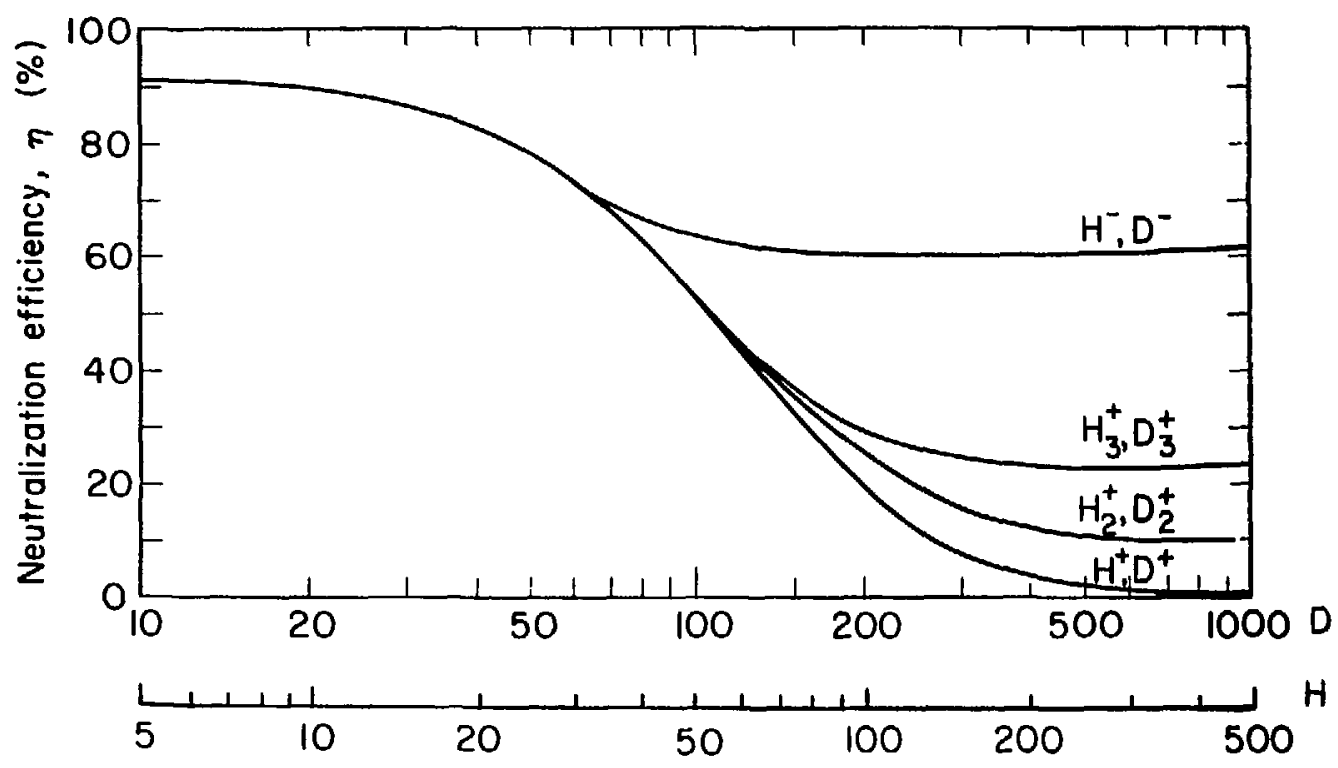

Energy of $H$ or $D$ atoms (keV) Figure 2. 


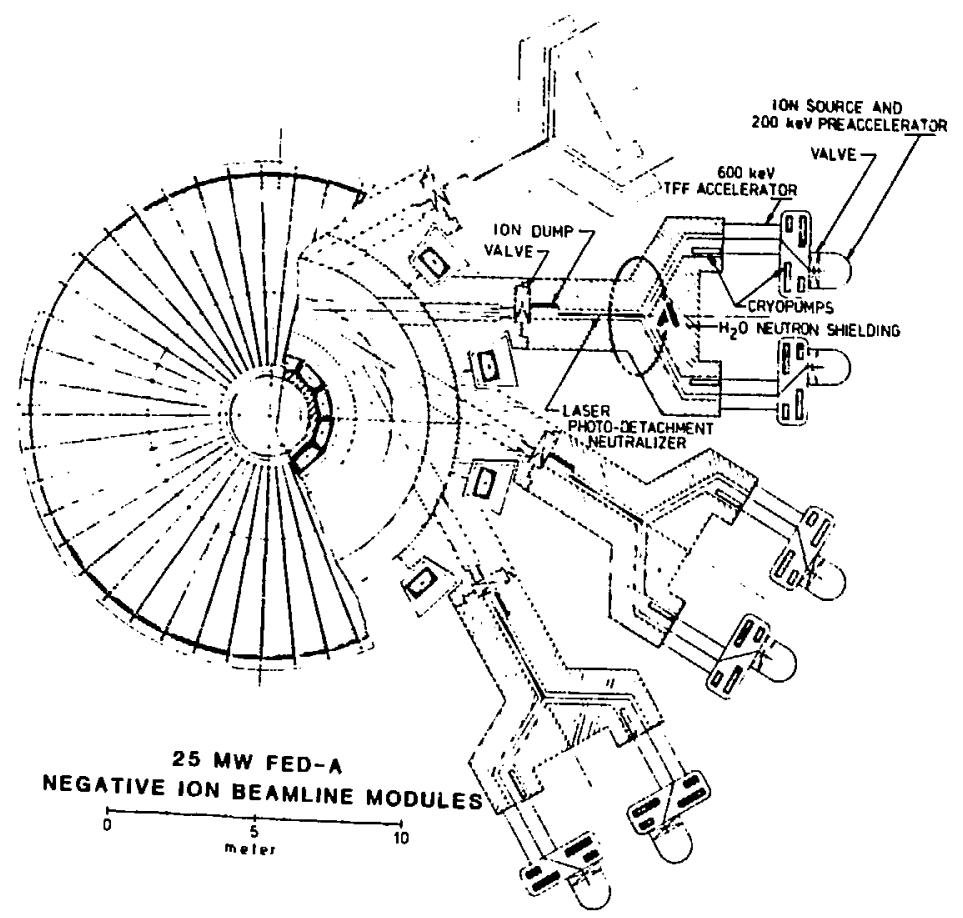

Figure 3.

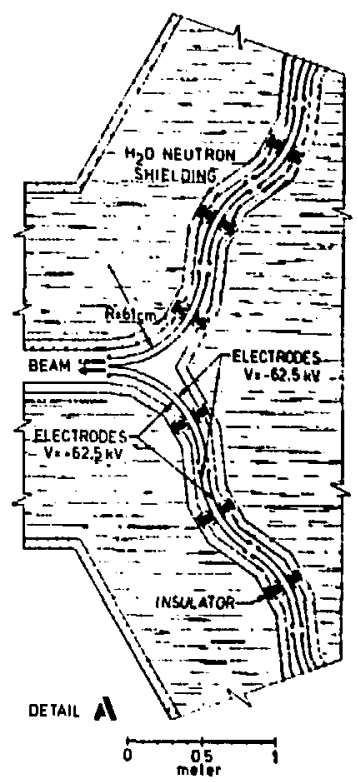

TFF BEAM TRANBPORT 


\section{SOURCE APPROXIMATION DIAGRAM}

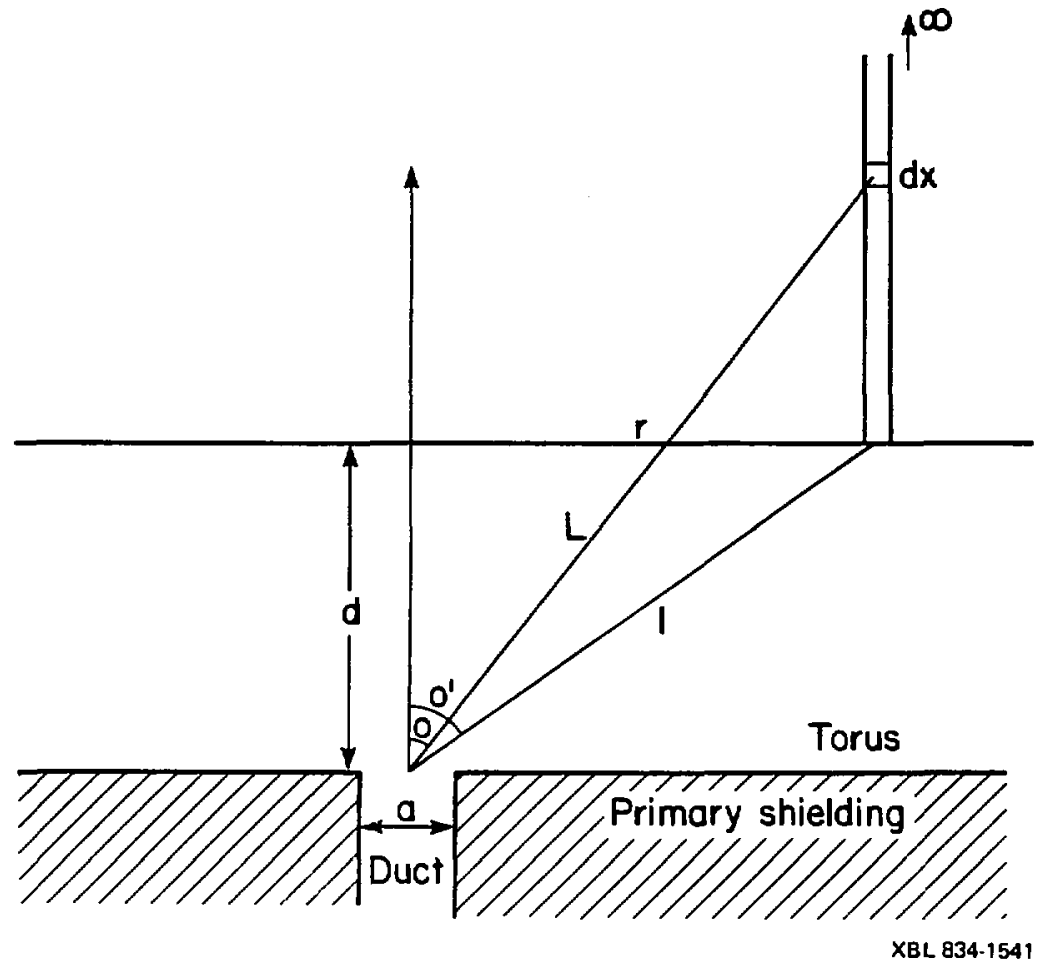

Figure 4 . 
DUCT GEOMETRY : PROFILE

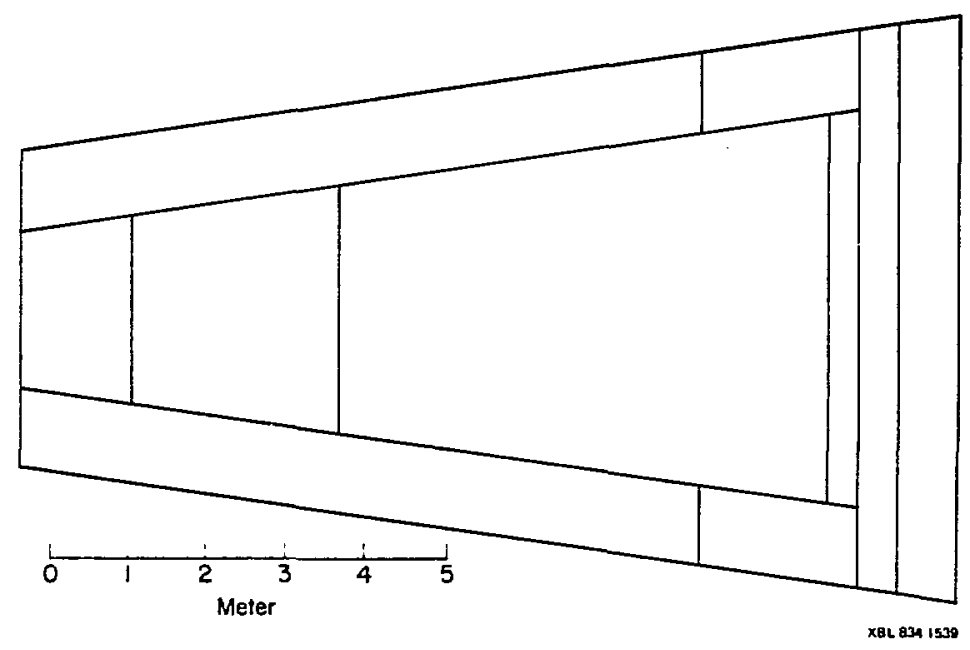

Figure 5. 


\section{DUCT GEOMETRY : PLAN VIEW}

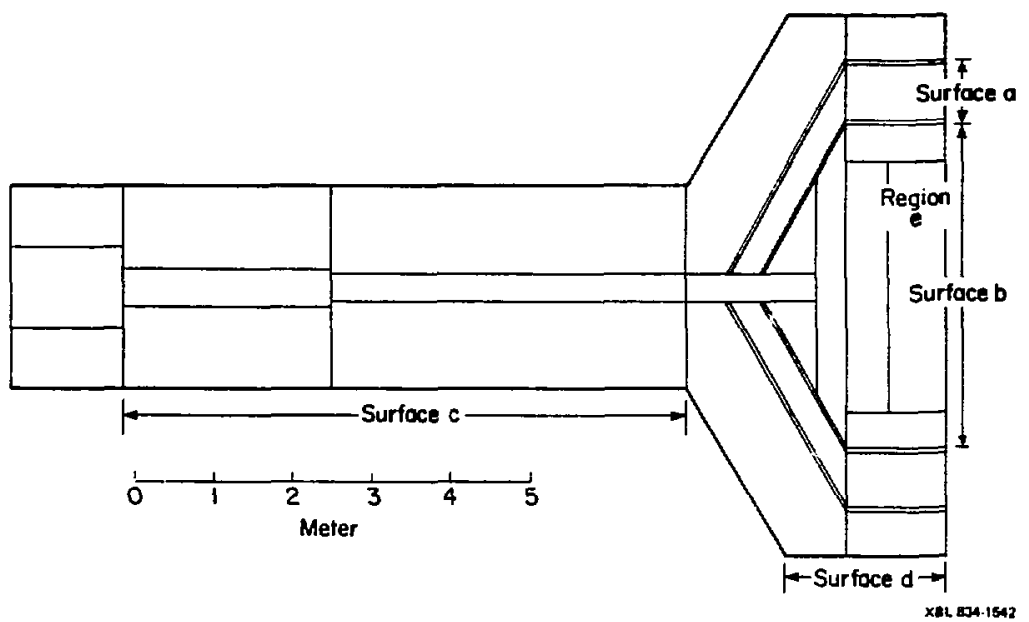

Figure 6. 


\section{DUCT GEOMETRY : PART I}

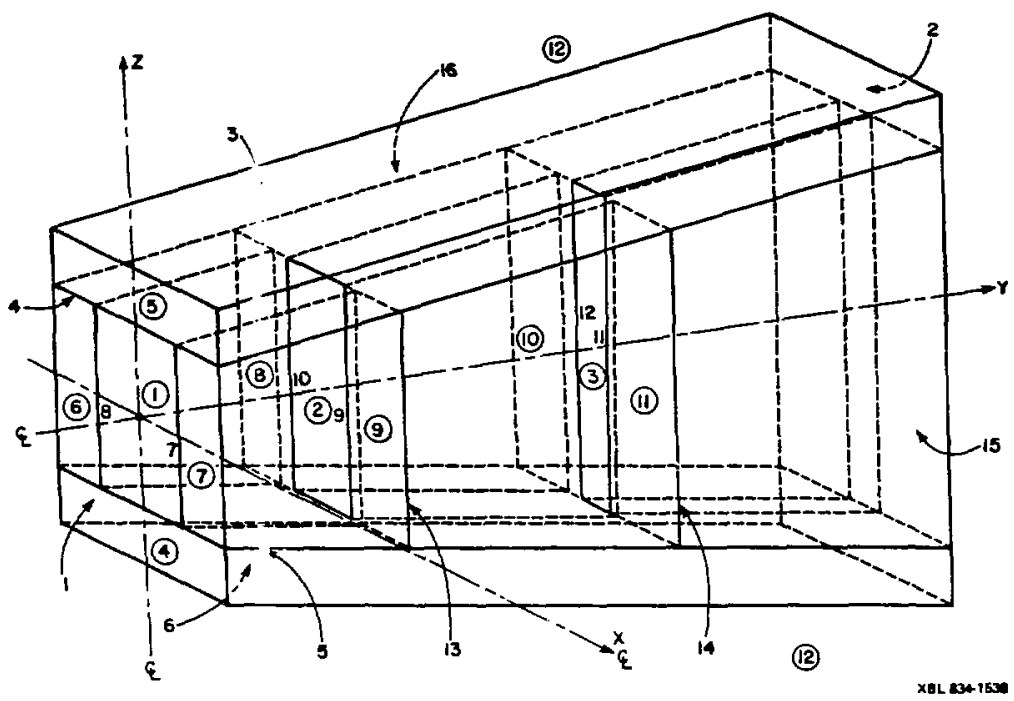

Figure 7 . 
DUCT GEOMETRY: PART 2

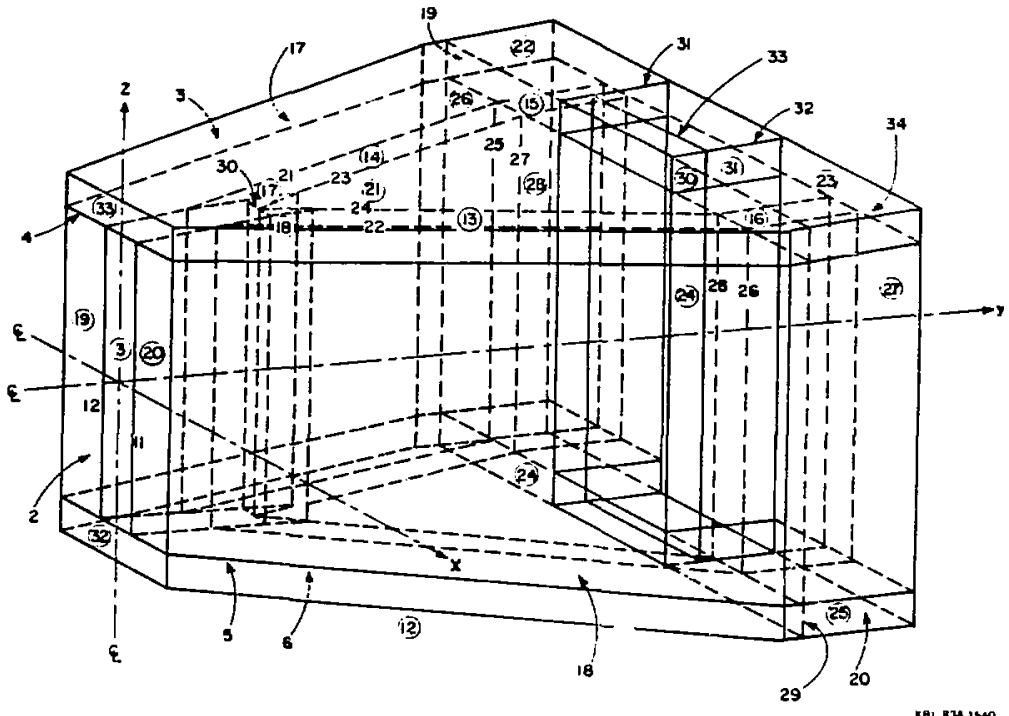

Figure 8. 
DUCT GEOMETRY: REENTRY DUCT AND LWERS

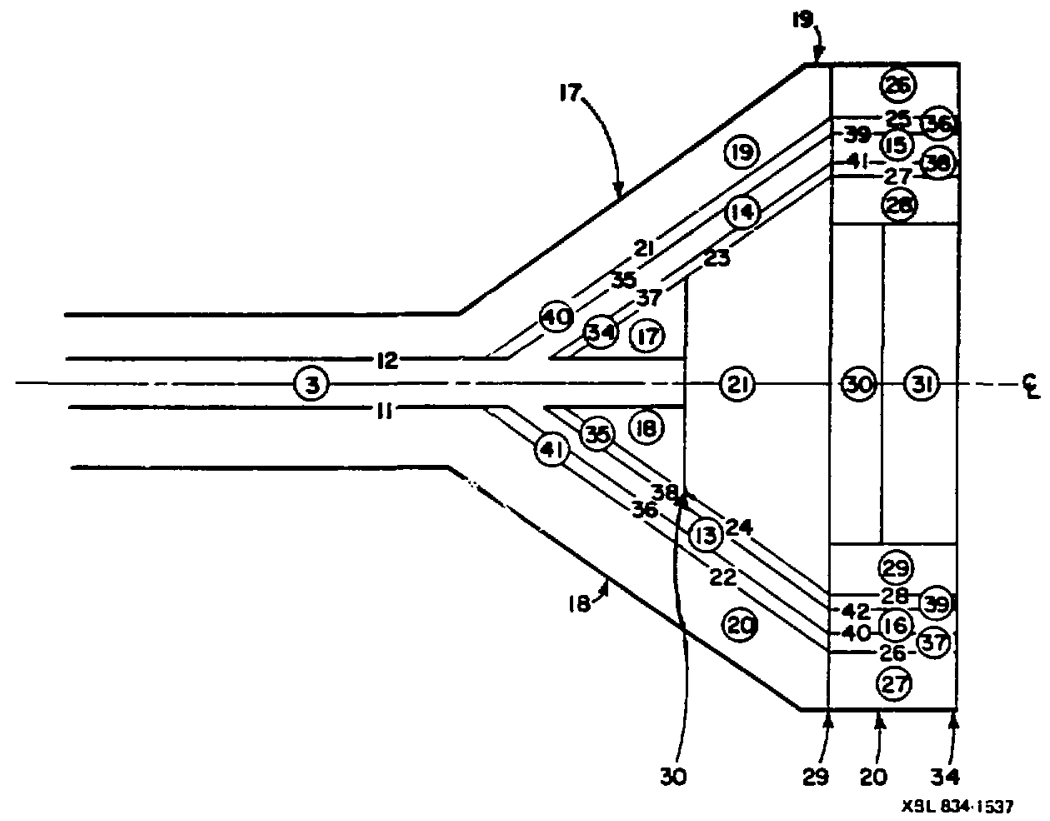

Figure 9. 